\title{
The application of a selection of decision-making techniques by employees in a transport work environment in conjunction with their perceived decision-making success and practice
}

\author{
Author: \\ Theuns F.J. Oosthuizen ${ }^{1}$ \\ Affiliation: \\ ${ }^{1}$ Department of Transport \\ and Supply Chain \\ Management, University of \\ Johannesburg, South Africa \\ Correspondence to: \\ Theuns Oosthuizen \\ Email: \\ toosthuizen.futuregroup@ \\ gmail.com \\ Postal address: \\ PO Box 358, Westhoven \\ 2142, South Africa \\ Dates: \\ Received: 15 Aug. 2013 \\ Accepted: 06 Feb. 2014 \\ Published: 17 Mar. 2014 \\ How to cite this article: \\ Oosthuizen, T.F.J., 2014, 'The \\ application of a selection of \\ decision-making techniques \\ by employees in a transport \\ work environment in \\ conjunction with their \\ perceived decision-making \\ success and practice', Journal \\ of Transport and Supply \\ Chain Management 8(1), Art. \\ \#118, 9 pages. http://dx.doi. \\ org/10.4102/jtscm.v8i1.118

\section{Copyright:} \\ (C) 2014. The Authors. \\ Licensee: AOSIS \\ OpenJournals. This work \\ is licensed under the \\ Creative Commons \\ Attribution License.
}

Read online:

Scan this $Q R$ code with your smart phone or mobile device to read online.
A lack of optimum selection and application of decision-making techniques, in conjunction with suitable decision-making practice and perception of employees in a transport work environment demands attention to improve overall performance. Although multiple decisionmaking techniques exist, five prevalent techniques were considered in this article, namely the Kepner-Tregoe, Delphi, stepladder, nominal group and brainstorming techniques. A descriptive research design was followed, using an empirical survey which was conducted among 210 workers employed in a transport work environment and studying in the field of transport management. The purpose was to establish to what extent the five decisionmaking techniques are used in their work environment and furthermore how the decisionmaking practice of using gut-feel and/or a step-by-step decision-making process and their perception of their decision-making success relate. The research confirmed that the use of decision-making techniques is correlated to perceived decision-making success. Furthermore, the Kepner-Tregoe, stepladder, Delphi and brainstorming techniques are associated with a step-by-step decision-making process. No significant association was confirmed between the use of gut-feel and decision-making techniques. Brainstorming was found to be the technique most frequently used by transport employees; however, it has limitations as a comprehensive decision-making technique. Employees working in a transport work environment need training in order to select and use the four comprehensive decision-making techniques.

\section{Introduction}

Decision-making forms part of the daily activities of all management and non-management employees in a transport work environment, as in all organisations (Quick \& Nelson 2013; Yuzhong \& Guangming 2012). As employees differ, their approach to decision-making could also differ (Nankervis 2008). Scope, technique and practice of decision-making as well as content of decisions made in an organisational context vary depending on whether the decisions are made by management or non-management employees (Hellriegel et al. 2012; Knemeyer \& Naylor 2011; Oosthuizen 2013). Effective decision-making can be established using decision-making techniques (Lussier 2012; Oosthuizen 2013). These decision-making techniques can be described as quantitative and qualitative aids used to assist individuals and groups in optimising decisionmaking effectiveness and success (Hellriegel et al. 2012). Qualitative techniques are normally used for generating alternative solutions for decision-making based on subjective opinions whereas quantitative techniques are based on objective mathematical analysis of alternative solutions (Lussier 2012).

Investigating the use of decision-making techniques in an organisational context, the transport work environment is identified as a broad focus area for research based on its critical economic and social contribution (Nieuwenhuizen \& Oosthuizen 2012). Considering the background provided, this research paper focuses on investigating the use of a selection of five decisionmaking techniques in a transport work environment and any possible relation with employees' perception of their decision-making success, their decision-making practice based on gut-feel and/or a step-by-step decision-making approach.

\section{Research problem}

A 'decision' refers to a choice between possible alternatives (Daft 2010). Furthermore, the concept 'decision-making' refers to the process of identifying problems and opportunities, finding solutions and taking action to resolve or address them (Daft 2010; Knemeyer \& Naylor 2011; Lussier 2012). Hellriegel et al. (2012:268) state that decision-making includes 'the ability to define 
problems, gather information, generate alternatives and choose a course of action'. Decision-making success in a transport work environment is dependent on the selection of the most appropriate solution to solve the problem, taking into consideration all the elements in the relevant transport and supply chain context (Strydom 2011; Wadhwa, Saxenay \& Chanz 2008).

The decision-making effectiveness of employees in the transport work environment is not optimal. It is a result of the assumption that these employees have the skills to practice decision-making and therefore select the appropriate decision-making technique (Knemeyer \& Naylor 2011). The lack of decision-making skills negatively impacts on overall performance of employees and organisations in the transport industry (Yuzhong \& Guangming 2012). The result of bad decisions made by employees working in a transport and supply chain work environment includes negative outcomes such as problems, error, bad performance and ineffectiveness (Kaufmann, Carter \& Buhrmann 2011). Improving decisionmaking skills through the use of established decisionmaking techniques will empower employees in the transport work environment to overcome these negative outcomes and improve their decision-making practice, effectiveness and genuine perception. This, in combination with the application of an integrated decision-making process, will allow employees in a transport work environment to develop the necessary experience to create a balanced and objective strategy for decision-making which will support overall performance (Hellriegel et al. 2012; Herbon et al. 2012).

\section{Research objective}

The primary objective of the research is to establish to what extent a selection of decision-making techniques is used by employees in a transport work environment and how the use of gut-feel in decision-making, a step-by-step decisionmaking process, and perception of their decision-making success relate. These decision-making techniques are:

- Kepner-Tregoe technique

- Delphi technique

- stepladder technique

- nominal group technique

- brainstorming technique.

The secondary objectives of the research are to determine to what extent employees in a transport work environment use a decision-making technique and:

- perceive their decision-making success to be very good

- use gut-feel for decision-making purposes

- use a step-by-step decision-making process.

\section{Literature review}

Decision-making is seen as a process and not merely the destination or the decision (Daft 2010). A rational decisionmaking process refers to a logical and structured stepby-step process which is followed in order to make a final choice or decision (Daft 2010; Lussier 2012). Furthermore, a rational process requires a sequence of steps, meaning that each of these steps should be followed in a particular order or sequence in order to optimise the outcome of the decision. If the sequence of events is changed, it will most likely jeopardise the outcome of that decision (Lussier 2012; Williams 2010). Successful decision-making is exposed to a broad base of elements.

Various factors negatively contribute to performance in the transport industry. One of these factors is a lack of skill development in decision-making and specifically the identification and application of suitable decision-making techniques for optimal decision-making practices within the transport work environment (Kaufmann et al. 2011). Haynie and Shepherd (2009) confirm that decision-making is an important responsibility of employees and could directly impact positively or negatively on their performance. Furthermore, the effectiveness of employees' decisionmaking is directly influenced by the quality of decisions made by them (Lussier 2012). Bad decisions made by employees in a transport work environment are as a result of various factors and result in a broad variety of negative outcomes, such as problems, error, bad performance and ineffectiveness (Kaufmann et al. 2011). The lack of training in the selection and use of decision-making techniques limits the opportunity to turnaround the practice of ineffective decision-making. Appropriate decision-making skills training is therefore critical to ensure overall organisational success (Useem, Cook \& Sutton 2005).

Considering the level of participation in decision-making it is possible to differentiate between individual and group decision-making, and in general there is an increasing shift to employee participation in decision-making (Lam, Chen \& Schaubroeck 2003). Group decisions made in a transport work environment, requiring the involvement of employees, could range from managerial to non-managerial level, have a strategic or operational focus, and include aspects such as transport planning, mode selection and even general everyday operational practices such as selecting a suitable driver for a specific route. Decision-making techniques supporting these types of decisions can be broadly clustered as group decision-making techniques (Lussier 2012). In an organisational context, group decision-making techniques allow for optimum performance of employees (management and non-management) working together in a team context such as a transport work environment (Ireland \& Miller 2004).

Although a broad base of decision-making techniques exists, five decision-making techniques were nominated for the research project and selected for their ability to support practices of group decision-making and their capacity to assist during a rational decision-making process which could be used in a transport work environment. These five techniques, namely the Kepner-Tregoe technique, the Delphi technique, the stepladder technique, the nominal group technique (NGT) and brainstorming (Hellriegel et al. 2012; Lussier 2012; Williams 2010), can be used to assist employees working in 
a transport work environment to generate creative decision alternatives and/or analyse possible alternatives and/or make a final selection of the most feasible alternative during a rational decision-making process.

\section{Kepner-Tregoe technique}

The first technique selected is the Kepner-Tregoe decisionmaking technique, which allows for a balanced rational approach including objective and subjective measures (Decision-making confidence 2013). It is a technique for comparing alternatives using measuring criteria developed early on in the process which consists out of four sequential steps (Lussier 2012; Zhang et al. 2002). The decisionmakers should establish their 'must' and 'want' criteria beforehand. 'Must' criteria are essential and not negotiable while 'want' criteria are important but not essential when making the decision. It is advisable that representatives of all stakeholders involved should participate in developing and agreeing to these two sets of criteria. The importance of each 'want' criterion is rated on a scale of 1 to $10 ; 1$ is not important and 10 is very important. Once the criteria are established the actual alternatives are rated. 'Must' criteria are rated using a 'yes/no' scale indicating whether the alternative meet the criteria or not (Zhang et al. 2002). Any alternative rated as 'no', in other words not meeting the criteria, will no longer be considered as an alternative and therefore be removed (Luo 2008). 'Want' criteria are rated on a scale of 1-10; 1 indicates a low rating of the alternative in terms of the criteria and 10 indicates a high rating. Once all alternatives are rated against the 'want' criteria the weighted score is calculated by multiplying the 'want' criteria score for each alternative and the importance score of each criterion. The total weighted score for each alternative is then calculated by adding the values of all the weighted scores for a particular alternative. The alternative with the highest weighted score is then confirmed the best solution (Kepner \& Tregoe 2005). Techniques such as brainstorming, NGT or the Delphi technique can be used in association with this decisionmaking technique.

\section{Delphi technique}

The Delphi technique was developed as a method for involving people who cannot come together physically in decision-making (Bardhan, Ngeru \& Pitts 2012; Hellriegel et al. 2012). This decision-making technique allows the use of experts, clients or other stakeholders too many to handle in a small group setting or who are separated by distance or schedule difficulty. Delphi is a series of questionnaires, the first of which presents a broad question (Hellriegel et al. 2012). Responses to the first questionnaire form the basis for a follow-up questionnaire. The second questionnaire begins to establish consensus by asking respondents to select a subset of ideas for further analysis and/or clarification. There may be several follow-up questionnaires in the Delphi process (Bardhan et al. 2012; Hellriegel et al. 2012). Unlike brainstorming or NGT, the Delphi technique can provide anonymity and confidentiality to the respondents if desired (Lussier 2012). The Delphi technique can be very time consuming based on time for response and preparation of follow-up questionnaires. The value of this continuous process is to establish consensus regarding a particular problem and decision through anonymous interaction. Selecting the relevant and appropriate experts on the panel and ensuring their anonymity is of great importance (Litchfield 2008).

\section{Stepladder technique}

The third technique considered is the stepladder technique, which aims to improve group decision-making by ensuring that each member's contribution is independent, and is considered and discussed by the group (Rogelberg, O'Conner \& Sedergurg 2002). This technique can be described as a decision-making technique in which group members are added to a group discussion one at a time - the existing group members listen to each new member's thoughts, ideas and recommendations; then the group shares the ideas and alternative suggestions that it had already considered, discuss the new and old ideas, and finally makes a decision (Williams 2010). For this technique to be effective all members of the group must have enough time to consider the problem or decision on their own, to present their ideas to the other group members, and to discuss all ideas and alternatives at each of the steps in the 'ladder'. Furthermore, decisionmakers should ensure that each member who joins the group bring independent ideas and suggestions (Winquist \& Franz 2008). A way of ensuring this is to guarantee that subsequent group members joining as the process continues, are unaware of the previous discussions and suggestions (Williams 2010).

\section{Nominal group technique}

The fourth decision-making technique considered for the purpose of this article is the nominal group technique (NGT). NGT is a technique for generating alternatives but it also allows decision-makers to evaluate alternatives in order to propose a solution and make a decision (Harvey \& Holmes 2012). NGT has been widely applied in industry, government, health care and educational environments (Dennis \& Valicich 1994). NGT can be defined as 'a process of generating and evaluating alternatives using a structure voting method' (Lussier 2012:102). This technique consists of six sequential steps (Harvey \& Holmes 2012; Lussier 2012). The first step involves the presentation of a problem. In the second step, group members individually and silently put their ideas in writing. The term 'nominal' refers to this part of the process. Though group members are in the same room, they are working independently. After the group has stopped writing, ideas are voiced in round-robin fashion until all members have stated their ideas. The ideas are recorded and presented, for example, on a flip chart. General discussion and clarification of the ideas follow. The group members individually rank the alternatives by priority. If desired, evaluation of alternatives and selection of one or more alternatives for implementation may follow (Roeden, Maaskant \& Curfs 2012). The group leader then writes the priorities on a board and allows voting to be conducted based on these priorities. NGT allows each group member 
to discuss and analyse the alternatives, and every participant has a similar role in the selection of the alternative. It is important that alternatives receive adequate clarification and discussion, so considerable time can be consumed. After discussion, participants individually vote by ranking or rating the alternatives (Harvey \& Holmes 2012).

\section{Brainstorming}

The final technique selected is brainstorming. Brainstorming is sometimes not seen as a typical decision-making technique, but as a technique that can be used in association with the other decision-making techniques (Daft 2010; Yazdani \& Tavakkoli-Moghaddam 2012). Brainstorming is used for developing creative alternatives; however, the aim is not to subsequently select one of these alternatives during the brainstorming process. Therefore, the alternatives are not evaluated and neither is a final choice made (Akdere 2011; Lussier 2012). Consequently brainstorming is less comprehensive and could be easily used along with any of the other techniques which are designed for actual selection during the decision-making process (Litchfield 2008). In order to ensure effective application of this technique, four essential rules need to be followed, (1) no discussion or evaluation of the alternative presented during the session is allowed, (2) freewheeling is encouraged - therefore ideas should be presented without considering their practicality, (3) quantity is required - the more ideas the better, and (4) the combination of ideas and building on other ideas are encouraged as this support creative thought (Hellriegel et al. 2012; Yazdani \& Tavakkoli-Moghaddam 2012).

\section{Research strategy \\ Research approach and research instrument}

The research is descriptive in nature and focused on existing decision-making techniques and practices. The research included a literature study presenting secondary data as framework for the empirical study. A structured questionnaire was designed and a quantitative research approach was applied during the empirical study. The questionnaire consisted of two sections. Section A considered the relevant demographic factors identified for the research project which aimed to establish the current position of the respondents within the organisation, their highest qualification, gender and age. Section B investigated the application of a selection of five decision-making techniques identified within the literature study, including the (1) Kepner-Tregoe, (2) Delphi, (3) stepladder, (4) nominal group and (5) brainstorming techniques. Section B furthermore presented questions aimed at examining the respondents' perception of their own (6) decision-making success as well as their decision-making practice which focused on the use of (7) gut-feel versus (8) a step-by-step decision-making approach. A three-point Likert intensity scale was used for Section B of the questionnaire. Each response was assigned a numerical score to reflect its degree of favourable attitude, ranging from 1 (always to most of the time) to 3 (seldom to never).

\section{Selection of respondents}

The aim of sampling is to select some of the elements in a population in order to draw conclusions about the entire population, whereas with a census a count of all the elements in a population is done (Cooper \& Schindler 2001). Considering the ease of access to respondents a census was considered appropriate. The study focused on management and non-management employees currently working in a transport work environment. Furthermore, only employees currently developing their academic skills and abilities by means of further studies in the field of transport management were considered. Therefore it can be concluded that the target population was employed individuals working in a transport environment and studying as a final-year student for the diploma in transport management, attending the study school. The size of the population was 248 students registered for a diploma in transport management at a study school. A census was conducted among 210 final-year students who attended the annual study school for the diploma in transport management presented in Johannesburg, Durban and Cape Town and who met all relevant criteria. The response rate was $84.6 \%$.

\section{Method of data collection}

There are several ways in which data can be collected from respondents when using the survey methodology, including personal collection, mail, the Internet and telephonic collection (Zikmund \& Babin 2007). Due to ease of access during study school a paper-based questionnaire was made available to attendees at the end of a session and was completed anonymously. The questionnaire was distributed personally to each respondent. It was self-administered by the researcher after the sample group attended a morning session during the annual study school. The research was only conducted among attending individuals who at that stage were employed in a transport work environment and were registered for the final year in the diploma in transport management.

\section{Data analysis strategy}

The data analysis strategy focused on obtaining optimum quality information to support the research objectives. Descriptive statistics were compiled in order to provide a summary of the research sample in terms of the variables of interest (Diamantopoulos \& Schlegelmilch 2000). The descriptive analysis was done by means of a frequency analysis, and tests of normality were done to investigate normal distribution of data using Kolmogorov-Smirnov and Shapiro-Wilk tests (Pallant 2005). In order to do a test for reliability, exploratory factor analysis was conducted to obtain initial information on the interrelationships among items of the proposed construct. To test unidimensionality, which is an underlying assumption of reliability, principle axis factoring was selected as factor analysis extraction method (Diamantopoulos \& Schlegelmilch 2000). The reliability test that was done consequently was used to test internal consistency between specific items of the identified 
construct, and was based on the calculation of a Cronbach's alpha score (Burns \& Burns 2008). Lastly, the data analysis strategy focused on establishing the existence and strength of associations between categorical variables of interest measured on the nominal or ordinal scale. For this purpose cross-tabulations were compiled and chi-square tests of independence conducted (Cooper \& Schindler 2001).

\section{Data analysis and discussion}

The research analysis was prepared using SPSS software and done by Statkon, a statistical consultation service at the University of Johannesburg. The analysis focused on the different decision-making techniques identified. The respondents' perceived decision-making success and their decision-making practice were also analysed. Analysis was also considered in terms of various demographic factors of respondents.

\section{Reliability analysis of the 'decision-making techniques' construct}

The concept 'reliability' refers to the degree to which an instrument or measure is free from random error, and is thus able to provide consistent data (McDaniel \& Gates 2006). For the purpose of this research, a test for reliability was done to verify the reliability of the data of a particular construct. In order to determine reliability, Cronbach's alpha, which measures the internal consistency of items, in other words how well a set of items measures a specific construct, was used (Burns \& Burns 2008). A high score indicates that the items are measuring the same construct, and therefore it indicates that reliability exists. According to Hair et al. (2006), an alpha value of greater than 0.7 indicates a higher degree of reliability.

The construct tested was based on a section of the literature research which focused on a selection of five decision-making techniques. The construct 'decision-making techniques' included the following decision-making techniques (items 1-5), (1) the Kepner-Tregoe technique; (2) the Delphi technique; (3) the stepladder technique; (4) the nominal group technique (NGT); and (5) the brainstorming technique.

The analysis indicated that the construct 'decision-making techniques', including all five items, was confirmed with a Cronbach's alpha score of 0.743 (see Table 1).

Although the reliability of the construct was confirmed, it should be noted that the communality extracted for item 5 (brainstorming), was less than 0.300 . Item 5 proved to be an ill-fitting item in the construct. Removing item 5, ensured goodness of fit and the factor structure improved. It furthermore allowed for zero redundant residuals and ensured that all four items contributed to internal consistency. The adapted construct therefore included only the first four techniques (items 1-4), namely the Kepner-Tregoe, Delphi, stepladder and nominal group techniques. The reliability calculated for this four-item construct 'decision-making techniques', excluding brainstorming, was confirmed with a Cronbach's alpha score of 0.744 (see Table 2).
TABLE 1: Reliability statistics: Cronbach's alpha for five-item construct.

\begin{tabular}{lll}
\hline Cronbach's alpha & Cronbach's alpha: Standardised items & $N$ of items \\
\hline 0.743 & 0.743 & 5 \\
\hline
\end{tabular}

TABLE 2: Reliability statistics: Cronbach's alpha for four-item construct.

\begin{tabular}{lll}
\hline Cronbach's alpha & Cronbach's alpha: Standardised items & $N$ of items \\
\hline 0.744 & 0.746 & 4 \\
\hline
\end{tabular}

As mentioned in the literature review, various opinions exist on whether brainstorming is a comprehensive decisionmaking technique or merely a supportive decision-making technique. Therefore, for further analysis and discussion, brainstorming was considered a supportive technique for decision-making purposes and not a pure decision-making technique.

\section{Frequency of demographic factors}

The demographic factors considered for analysis were the respondents' current management versus non-management position within the organisation, highest qualification, gender and age. Key demographic results indicated that the respondents working in a transport working environment were more or less equally represented in terms of management (51\%) versus non-management $(49 \%)$ positions. More than $50 \%$ of the respondents had at least a matric or grade 12 qualification and more than $30 \%$ of respondents had already obtained a diploma as their highest qualification. Two-thirds of the respondents were male and one-third female. Almost $80 \%$ of respondents fell within the combined age group of 26-49 years of age. The largest age group represented was that of 36-49 years of age.

\section{Frequency of decision-making techniques}

Table 3 is a summary indicating the frequency of use of the five decision-making techniques identified during the literature study and tested in Section B of the questionnaire. The results were articulated using a three-point Likert scale.

Analysing the frequencies presented in Table 3, it was noticeable that brainstorming was most frequently used by respondents working in a transport work environment (50.0\% - always to most of the time), whereas the KepnerTregoe technique was used least (43.6\% - seldom to never).

\section{Decision-making techniques versus perception and practices}

Using cross-tabulations and the application of the Pearson's chi-square non-parametric test of significance, significant association could be established among categories identified. This allowed for further investigation of the various decisionmaking techniques versus the perception of decision-making success and the two decision-making practices of using gutfeel and using a step-by-step process.

With cross-tabulation it was found that $63.0 \%$ of respondents who perceived their decision-making success at work to be very good (always to most of the time) made use of the 
TABLE 3: Frequencies: Use of decision-making techniques.

\begin{tabular}{|c|c|c|c|c|}
\hline Use of decision-making techniques & Always to most of the time & Sometimes & Seldom to never & Total \\
\hline I have used the Kepner-Tregoe technique for decision-making purposes at my work place. & $14.9 \%$ & $41.5 \%$ & $43.6 \%$ & $100.0 \%$ \\
\hline I have used the Delphi technique for decision-making purposes at my work place. & $16.4 \%$ & $45.5 \%$ & $38.1 \%$ & $100.0 \%$ \\
\hline I have used the Stepladder technique for decision-making purposes at my work place. & $24.5 \%$ & $41.5 \%$ & $34.0 \%$ & $100.0 \%$ \\
\hline I have used the Nominal group technique for decision-making purposes at my work place. & $26.2 \%$ & $46.6 \%$ & $27.2 \%$ & $100.0 \%$ \\
\hline I have used the Brainstorming technique for decision-making purposes at my work place. & $50.0 \%$ & $37.0 \%$ & $13.0 \%$ & $100.0 \%$ \\
\hline
\end{tabular}

Kepner-Tregoe technique. This rate was much lower (25.9\%) for respondents who made use of gut-feel when making decisions (always to most of the time) using the KepnerTregoe technique. Three-quarters $(75.4 \%)$ of respondents who used a step-by-step decision-making process for their decision-making at work (always to most of the time) made use of the Kepner-Tregoe technique. The cross-tabulation analysis yielded four degrees of freedom. Using a Pearson's chi-square test, a significant association at the $95.0 \%$ confidence interval $(p=0.008<0.050)$ was found between respondents using the Kepner-Tregoe technique and the use of a step-by-step decision-making process (see Table 4). Phi was used to confirm strength of association between the variables. According to Cohen (1988), a Phi of 0.10-0.29, on a scale where 0 indicates no association and 1 a strong association, indicates a weak association. In this case it was found that Phi $=0.274$, indicating a weak association.

Analysing cross-tabulations, $56.7 \%$ of respondents who perceived the success of their decision-making at the work place to be very good (always to most of the time) made use of the Delphi technique. This rate was much lower (29.0\%) for respondents who made use of gut-feel when making decisions (always to most of the time) using this decisionmaking technique. Furthermore, $70.0 \%$ of respondents who used a step-by-step decision-making process at the work place (always to most of the time) made use of the Delphi technique. The cross-tabulation analysis yielded four degrees of freedom. Using a Pearson's chi-square test, a significant association at the $95 \%$ confidence interval (CI) $(p=0.004<$ 0.05) was found between respondents using the Delphi technique and using a step-by-step decision-making process (see Table 5). Phi was used to confirm strength of association between the variables. According to Cohen (1988), a Phi of $0.10-0.29$, on a scale where 0 indicates no association and 1 a strong association, indicates a weak association. In this case it was found that Phi $=0.286$, indicating a weak association.

Examining cross-tabulations, $60.5 \%$ of respondents who perceived their decision-making success at work to be very good (always to most of the time) made use of the stepladder technique. The cross-tabulation analysis yielded four degrees of freedom. Using a Pearson's chi-square test, a significant association at the $95 \% \mathrm{CI}(p=0.006<0.050)$ was found between respondents using the stepladder technique and perceiving their decision-making success at work to be very good (see Table 6). Phi was used to confirm strength of association between the variables. According to Cohen (1988), a Phi of $0.10-0.29$, on a scale where 0 indicates no association and 1 a strong association, indicates a weak association. In this case it was found that Phi $=0.284$, indicating a weak association.
TABLE 4: Kepner-Tregoe technique versus step-by-step decision-making process.

\begin{tabular}{lllll}
\hline Test & Value & $d f$ & $\begin{array}{l}\text { Asymp. sig. } \\
\text { (2-sided) }\end{array}$ & Approx. sig. \\
\hline Pearson's chi-square & 13.923 & 4 & 0.008 & - \\
Phi & 0.274 & - & - & 0.008 \\
\hline
\end{tabular}

Asymp. sig., Asymptotic significance; Approx. sig., Approximate significance.

TABLE 5: Delphi technique versus step-by-step decision-making process.

\begin{tabular}{lllll}
\hline Test & Value & $d f$ & $\begin{array}{l}\text { Asymp. sig. } \\
\text { (2-sided) }\end{array}$ & Approx. sig. \\
\hline Pearson's chi-square & 15.301 & 4 & 0.004 & - \\
Phi & 0.286 & - & - & 0.004 \\
\hline
\end{tabular}

Asymp. sig., Asymptotic significance; Approx. sig., Approximate significance.

TABLE 6: Stepladder technique versus perceived decision-making success.

\begin{tabular}{lllll}
\hline Test & Value & $d f$ & $\begin{array}{l}\text { Asymp. sig. } \\
\text { (2-sided) }\end{array}$ & Approx. sig. \\
\hline Pearson's chi-square & 14.522 & 4 & 0.006 & - \\
Phi & 0.284 & - & - & 0.006 \\
\hline
\end{tabular}

Asymp. sig., Asymptotic significance; Approx. sig., Approximate significance.

TABLE 7: Stepladder technique versus step-by-step decision-making process.

\begin{tabular}{lllll}
\hline Test & Value & $d f$ & $\begin{array}{l}\text { Asymp. sig. } \\
\text { (2-sided) }\end{array}$ & Approx. sig. \\
\hline Pearson's chi-square & 18.169 & 4 & 0.001 & - \\
Phi & 0.313 & - & - & 0.001 \\
\hline
\end{tabular}

Asymp. sig., Asymptotic significance; Approx. sig., Approximate significance.

Considering cross-tabulations, the rate was much lower (22.2\%) for respondents who made use of gut-feel when making decisions (always to most of the time) using the stepladder technique. It was found that $71.7 \%$ of respondents who used a step-by-step decision-making process for their decision-making at work (always to most of the time) made use of the stepladder technique. The cross-tabulation analysis yielded four degrees of freedom. Using a Pearson's chi-square test, a significant association at the $95 \% \mathrm{CI}(p=0.001<0.050)$ was found for respondents using the stepladder technique and using a step-by-step process when making decisions (see Table 7). Phi was used to confirm strength of association between the variables. According to Cohen (1988), a Phi of $0.30-0.49$, on a scale where 0 indicates no association and 1 a strong association, indicates a medium association. In this case it was found that Phi $=0.313$, indicating a medium association.

Analysing cross-tabulations, $58.7 \%$ of respondents who perceived their decision-making success at work to be very good (always to most of the time) made use of the nominal group technique. This rate was much lower (21.7\%) for respondents who made use of gut-feel when making decisions (always to most of the time) using this decisionmaking technique. Also, $63.8 \%$ of respondents who used a step-by-step decision-making process at the work place (always to most of the time) made use of the nominal group 
technique. No significant association was found regarding the use of the nominal group technique.

Considering cross-tabulations, $54.3 \%$ of respondents who perceived their decision-making success at work to be very good (always to most of the time) made use of the brainstorming technique. The frequency is much lower $(21.0 \%)$ for respondents who made use of gut-feel when making decisions (always to most of the time) using the brainstorming technique. Furthermore, $69.5 \%$ of respondents who used a step-by-step decision-making process at the work place (always to most of the time) made use of the brainstorming technique. The cross-tabulation analysis yielded four degrees of freedom. Using a Pearson's chi-square test, a significant association at the $95 \% \mathrm{CI}(p=0.000<0.050)$ was found between respondents using the brainstorming technique and perceiving their decision-making success at work to be very good (see Table 8). Phi was used to confirm strength of association between the variables. According to Cohen (1988), a Phi of 0.5-1.0, on a scale where 0 indicates no association and 1 a strong association, indicates a strong association. In this case it was found that Phi $=0.523$, indicating a strong association.

Using a Pearson's chi-square test, a significant association at the $95 \%$ confidence interval $(p=0.000<0.050)$ was found between respondents using the brainstorming technique and respondents using a step-by-step decision-making process (see Table 9). Phi was used to confirm strength of association between the variables. According to Cohen (1988), a Phi of 0.5-1.0, on a scale where 0 indicates no association and 1 a strong association, indicates a strong association. In this case it was found that Phi $=0.510$, indicating a strong association.

\section{Value added}

The research adds value as it creates awareness of the need of transport management and employees to pay attention to the development of decision-making skills and practices in their working environment. Employees' assumptions about decision-making success need attention in order to establish effective and objective decision-making performance measurement. Furthermore, appropriate decision-making practices could be established by means of developing a suitable decision-making organisational culture within the transport work environment and establishing a continuous decision-making learning environment. This will allow each

TABLE 8: Brainstorming versus perceived decision-making success.

\begin{tabular}{lllll}
\hline Test & Value & $d f$ & $\begin{array}{l}\text { Asymp. sig. } \\
\text { (2-sided) }\end{array}$ & Approx. sig. \\
\hline Pearson's chi-square & 50.699 & 4 & 0.000 & - \\
Phi & 0.523 & - & - & 0.000 \\
\hline
\end{tabular}

Asymp. sig., Asymptotic significance; Approx. sig., Approximate significance.

TABLE 9: Brainstorming versus step-by-step decision-making process.

\begin{tabular}{lllll}
\hline Test & Value & $d f$ & $\begin{array}{l}\text { Asymp. sig. } \\
\text { (2-sided) }\end{array}$ & Approx. sig. \\
\hline Pearson's chi-square & 49.447 & 4 & 0.000 & - \\
Phi & 0.510 & - & - & 0.000 \\
\hline
\end{tabular}

Asymp. sig., Asymptotic significance; Approx. sig., Approximate significance. employee to develop not only individual decision-making skills but also decision-making skills which will allow them to contribute in a group context.

\section{Limitations}

The results presented are representative of the respondents who met the specific criteria while working in a transport environment and studying in the field of transport management. As this population is unique and not necessarily representative of the total South African transport employee population, it cannot be assumed that the results are representative of the whole industry. Respondents who are improving their academic skills are typically employees who will be developing decision-making skills. These respondents therefore could have a potential advancement over employees who are not furthering their studies or those who do not have any relevant qualifications or opportunity to develop these critical skills in-house while working in a transport work environment.

\section{Future research}

Future research could focus on investigating employees working in different modes within the transport industry. Differentiating between the different transportation modes could establish whether any diverse decision-making practices exist within the industry. This will allow for specific research on employees working in different transport modes regarding the use of decision-making techniques; their perceptions on their decision-making success; and their own decision-making practices. Research could also focus on specific decision-making techniques needed for practice within a transport work environment as well as the specific techniques that are more suitable at specific levels in the work environment. Differentiating between individual and group decision-making can also contribute to a better understanding of decision-making practices in this environment.

\section{Recommendations}

Employees working in a transport work environment need to develop their decision-making skills accordingly. This will empower them to optimise their performance and add value to the overall performance of the transport organisation. Objectivity is a critical attribute in evaluating performance; these employees' general perception of their decision-making success requires attention in order to ensure objective performance measurement practice. The decisionmaking techniques investigated are valuable for enhancing decision-making success and should improve the application of a step-by-step decision-making process in a transport work environment as well as the ability to participate in group decision-making. Therefore these techniques should form a critical component of decision-making practice, which will enhance employee performance. The general perception that gut-feel decision-making does not require the support of a structured decision-making approach requires attention and should be revisited. Employees working in a transport environment should not ignore the importance of using a 
step-by-step decision-making process in conjunction with a gut-feel approach. The application of a decision-making technique will guide the application of gut-feel in a more structured decision-making context. The ideal practice will allow these employees to integrate gut-feel, based on experience, with a logical step-by-step process and a suitable decision-making technique.

Training employees on both managerial and non-managerial levels in a transport work environment to use a broad base of appropriate decision-making techniques is critical and can be seen as a sustainable performance strategy to empower them in team context at operational and managerial levels, but also indirectly at the individual level.

Brainstorming is a popular technique used for decisionmaking purposes in most organisational contexts. Understanding its value as a supportive decision-making technique only will empower employees in a transport work environment when practicing optimal decision-making. Therefore training these employees in terms of the precise application of each technique will enhance their individual performance as well as their ability to participate in group context and contribute to group decisions. This will generate a long-term effect which will have a positive impact on the performance of the transport organisation, which could contribute to the creation of new best practices for a sustainable future.

\section{Conclusion}

This study has shown that respondents, employees in a transport work environment, most frequently use brainstorming as decision-making technique, while they use the Kepner-Tregoe technique least frequently. The same respondents only sometimes use the NGT and Delphi techniques. In comparison to the other techniques, the stepladder technique is rarely used. This multiplicity in use indicates the limited and/or fragmented exposure these employees have to the variety of potential decisionmaking techniques available for application in their work environment. The selection of the appropriate technique, for example understanding the difference in context such as individual versus group decision-making or quantitative versus qualitative decision-making, is as important as the choice to use decision-making techniques during the decision-making process.

Respondents indicated that they frequently make use of a step-by-step decision-making process but do not frequently use the Kepner-Tregoe, Delphi, NGT or stepladder decisionmaking techniques in conjunction. This trend does not represent an ideal work environment, as confirmed in the literature study. Only brainstorming is used frequently in conjunction with a step-by-step process. Not using a decision-making technique in conjunction with a step-bystep process indicates a fundamental weakness in decisionmaking practice in the transport industry, as confirmed in previous research presented in the literature review. The perception of respondents that they are successful decisionmakers while a large proportion of them is not frequently using most of the decision-making techniques, especially the more comprehensive techniques, creates concern. It impacts negatively on their ability to apply a step-by-step decisionmaking process optimally or even use techniques to support gut-feel during the decision-making process.

Confirmation of a significant correlation between the use of decision-making techniques and employees' perceived success in decision-making in this industry emphasises the importance of skill development in identifying, selecting and applying decision-making techniques. The application of various decision-making techniques should also take place in conjunction with a logical step-by-step decision-making process.

\section{Acknowledgements Competing interests}

The author declares that he has no financial or personal relationship(s) which may have inappropriately influenced him in writing this article.

\section{References}

Akdere, M. 2011 'An analysis of decision-making process in organizations: Implications for quality management and systematic practice', Total Quality Management 22(12), 1317-1330. http://dx.doi.org/10.1080/14783363.2011.62 5180

Bardhan, T, Ngeru, J. \& Pitts, R. Jr., 2011 'A Delphi multi-criteria decision making approach in the selection of an enterprise-wide integration strategy', Proceedings of the European Conference on Information Management \& Evaluation, Toronto, Canada, April 27-28, 2011, pp. 24-37.

Burns, R.B. \& Burns, R.A., 2008, Business research methods and statistics using SPSS, Sage, Los Angeles.

Cohen, J.W., 1988, Statistical power analysis for the behavioral sciences, 2nd edn., Lawrence Erlbaum, Hillsdale.

Cooper, D.R. \& Schindler, P.S., 2001, Business research methods, 7th edn., McGraw-Hill Irwin, Boston.

Daft, R.L., 2010, New era of management, 9th edn., Cengage Learning, Australia.

Decision-making confidence, 2013, Kepner Tregoe decision making: The steps, the pros and the cons, viewed 23 July 2013, from http://www.decisionThe steps, the pros and the cons, viewed 23 July 2013 , from http://
making-confidence.com/kepner-tregoe-decision-making.html.

Dennis, A.R. \& Valicich, J.S., 1994, 'Group, sub-group, and nominal group idea generation: New rules for a new media? Journal of Management 20 org $/ 10.1177 / 014920639402000402$

Diamantopoulos, A. \& Schlegelmilch, B.B., 2000, Taking the fear out of data analysis, Dryden Press, London.

Harvey, N. \& Holmes, C.A., 2012, 'Nominal group technique: An effective method for obtaining group consensus', International Journal of Nursing Practice 18, 188194. http://dx.doi.org/10.1111/j.1440-172X.2012.02017.x

Haynie, M. \& Shepherd, D.A., 2009, 'A measure of adoptive cognition for entrepreneurship research', Entrepreneurship Theory and Practice 33(3), 695714. http://dx.doi.org/10.1111/j.1540-6520.2009.00322.x

Hellriegel, D., Slocum, J., Jackson, S.E., Louw, L., Staude, G., Amos, T., Klopper, H.B., Louw, L. \& Oosthuizen, T., 2012, Management, 4th edn., Oxford University Press, Cape Town.

Herbon, A., Moalem, S., Shnaiderman, H. \& Templeman, J., 2012, 'Dynamic weights approach for off-line sequencing of supplier selection over a finite planning horizon', International Journal of Physical Distribution and Logistics Management 42(5), 434-463. http://dx.doi.org/10.1108/09600031211246500

Ireland, H.D., \& Miller, C.C., 2004, 'Decision-making and firm success', Academy of Management Executive 18(4), 8-12. http://dx.doi.org/10.5465/ AME.2004.15268665

Kaufmann, L., Carter, C.R. \& Buhrmann, C., 2011, 'The impact of individual debiasing efforts on financial decision effectiveness in the supplier selection process', International Journal of Physical Distribution and Logistics Management 42(5), 411-433. http://dx.doi.org/10.1108/09600031211246492

Kepner, C.H. \& Tregoe, B.B., 2005, The new rational manager, revised edn., KepnerTregoe, New York.

Knemeyer, A.M. \& Naylor, R.W., 2011, 'Using behavioral experiments to expand our horizons and deepen our understanding of logistics and supply chain decision making', Journal of Business Logistics 32(4), 296-302. http://dx.doi.org/10.1111/ j.0000-0000.2011.01025.x 
Lam, S.S.K., Chen, X.P. \& Schaubroeck, J., 2003, 'Participative decision making and employee performance in different cultures: The moderating effects of allocentrism/idiocentrism and efficacy', Academy of Management Journal 45(5), allocentrism/idiocentrism and efficacy', Academy
905-914. http://dx.doi.org/10.2307/3069321

Litchfield, R.C., 2008, 'Brainstorming reconsidered: A goal-based view', Academy of Management Review 33(3), 649-668. http://dx.doi.org/10.5465/ AMR.2008.32465708

Luo, C., 2008, 'Comparing Two Rational Decision-making Methods in the Process of Resignation Decision', The Journal of Human Resource and Adult Learning 4(1), $21-29$.

Lussier, R.N., 2012, Management fundamentals: Concepts, applications, skill development, 5th edn., South Western College Publishing, Cincinnati.

McDaniel, C. \& Gates, R., 2006, Marketing research essentials, 5th edn., Wiley, Hoboken.

Nankervis, A., 2008, 'Book review: International dimensions of organizational behaviour by N.J. Adler and A. Gunderson', Academy of Management Perspectives 22(1), 73-74. http://dx.doi.org/10.5465/ÁMP.2008.31217520

Nieuwenhuizen, C. \& Oosthuizen, T.F.J., 2012, Business management: A contemporary compilation, Future Vision Business Consultants, Johannesburg.

Oosthuizen, T.F.J., 2013, Management success: A task focus, 2nd edn., Future Vision Business Consultants, Johannesburg.

Pallant, J., 2005, SPSS survival manual: A step-by-step guide to data analysis using SPSS, 2nd edn., Allen \& Unwin, Crows Nest.

Quick, J.C. \& Nelson, D.L., 2013, Principles of organizational behaviour, 8th edn., Cengage Learning, Australia.

Roeden, J.M., Maaskant, M.A. \& Curfs, L.M.G., 2012, 'The nominal group technique as an evaluation tool for solution-focused coaching', Journal of Applied Research
in Intellectual Disabilities 25, 588-593. http://dx.doi.org/10.1111/j.14683148.2012.00696.x
Rogelberg, S., O'Conner, M. \& Sedergurg, M., 2002, 'Using the stepladder technique to facilitate the performance of audioconferencing groups', Journal of Applied Psychology 87, 994-1000. http://dx.doi.org/10.1037/0021-9010.87.5.994

Strydom, J., 2011, Principles of business management, 2nd edn., Oxford University Press, Cape Town.

Useem, M., Cook, J. \& Sutton, L., 2005, 'Developing leaders for decision-making under stress: Wildland firefighters in the South Canyon fire and its aftermath, Academy of Management Learning and Education 4(4), 461-485. http://dx.doi. org/10.5465/AMLE.2005.19086788

Wadhwa, S., Saxenay, A. \& Chanz, F.T.S., 2008, 'Framework for flexibility in dynamic supply chain management', International Journal of Production Research 46(6), 1373-1404. http://dx.doi.org/10.1080/00207540600570432

Williams, C., 2010, Managing effectively, 4th edn., Cengage Learning, Australia.

Winquist, J.R. \& Franz, T.M., 2008, 'Does the stepladder technique improve group decision making? A series of failed replications', Group Dynamics: Theory, Research, and Practice 12(4), 255-267. http://dx.doi.org/10.1037/10892699.12.4.255

Yazdani, A. \& Tavakkoli-Moghaddam, R., 2012, 'Integration of the fish bone diagram brainstorming, and AHP method for problem solving and decision making - A case study', Internal Journal of Advanced Manufacturing Technology 63, 651-657. http://dx.doi.org/10.1007/s00170-012-3916-7

Yuzhong, M. \& Guangming, Y., 2012, 'A study of outsourcing and self-run business decision making in the distribution transportation of international logistics' Energy Procedia, 16, 965-970. http://dx.doi.org/10.1016/j.egypro.2012.01.154

Zhang, X.Q., Kumaraswamy, M.M., Zheng, W. \& Palaneeswaran, E., 2002, 'Concessionaire selection for build-operate-transfer tunnel projects in Hong Kong', Journal of Construction Engineering and Management 128(1), 155-163. http://dx.doi.org/10.1061/(ASCE)0733-9364(2002)128:2(155)

Zikmund, W.G. \& Babin, B., 2007, Essentials of marketing research, Thomson SouthWestern, Australia. 